$\begin{array}{ll}\text { Cipango } & \text { Cipango } \\ \text { Cahiers d'études japonaises }\end{array}$

$22 \mid 2015$

Du particulier et de l'universel

\title{
In memoriam Fujimori Kiyoe
}

\section{Pascal Hurth}

\section{Q OpenEdition}

\section{Journals}

\section{Édition électronique}

URL : https://journals.openedition.org/cipango/2491

DOI : 10.4000/cipango.2491

ISSN : 2260-7706

\section{Éditeur}

INALCO

\section{Édition imprimée}

Date de publication : 1 janvier 2015

ISSN : 1164-5857

\section{Référence électronique}

Pascal Hurth, «In memoriam Fujimori Kiyoe », Cipango [En ligne], 22 | 2015, mis en ligne le 08 février 2019, consulté le 09 avril 2022. URL : http://journals.openedition.org/cipango/2491 ; DOI : https:// doi.org/10.4000/cipango.2491

\section{(ब) $(1)$}

Cipango est mis à disposition selon les termes de la Licence Creative Commons Attribution - Pas d'Utilisation Commerciale 4.0 International. 


\title{
In memoriam Fujimori Kiyoe
}

\author{
Pascal HuRTh
}

Madame Fujimori Kiyoe 藤森清江 nous a quittés le lundi 15 février 2016.

Diplômée de la faculté de Lettres classiques de l'université Ochanomizu Joshi Daigaku お茶の水女子大学 (université féminine d'Ochanomizu), elle fut recrutée en septembre 1959 comme responsable du fonds japonais de ce qui était à l'époque la Bibliothèque des langues orientales, devenue plus tard la Bibliothèque interuniversitaire des langues orientales et enfin la Bulac. Elle prit sa retraite en avril 1994. En parallèle, de 1969 à 1994, elle enseigna la langue classique à l'Inalco. Ses étudiants l'adoraient, elle se montrait à la fois rigoureuse et chaleureuse.

Son recrutement correspond à la renaissance du Japon et à l'augmentation des étudiants qui en découlait.

Bien que de 1951 à 1952 Jean Buhot (1885-1952), professeur à l'École du Louvre et chargé de cours aux Langues orientales, participa au classement du fonds japonais, jusqu'en septembre 1959, hormis l'acquisition d'ouvrages de base tels que des dictionnaires, manuels de grammaire ou d'histoire, la bibliothèque n'avait pas défini de véritable politique documentaire à l'égard du Japon, et les documents arrivaient en désordre. Le faible nombre d'étudiants inscrits aux Langues orientales explique cette situation.

À son arrivée, immédiatement, Madame Fujimori s'attela avec efficacité, énergie, minutie et rigueur à cette vaste tâche qu'était la constitution d'un fonds japonais digne de ce nom qui puisse rivaliser avec les collections des bibliothèques américaines. D'emblée, elle travailla avec la meilleure librairie de Tōkyō spécialisé dans l'exportation, Isseidō 一誠堂, fondée en 1903 avec laquelle 
14 Cahiers d'études japonaises $n^{\circ} 22$

elle sut établir une relation de confiance qui perdure encore aujourd'hui. Les premiers livres et périodiques de haut niveau arrivèrent au printemps 1960.

Faut-il rappeler qu'en ces temps lointains, toutes les opérations étaient manuelles?

Certes, Madame Fujimori, pure enfant de Tōkyō ou Edokko 江戸っ子 - ce dont elle tirait fierté -, connaissait Isseidō, mais la recherche bibliographique était ardue. En ces temps lointains, foin d'Internet et autres bases bibliographiques en ligne, le bibliothécaire en charge d'horizons éloignés devait faire preuve d'entregent et d'astuce, ce qu'elle fit à merveille avec une aisance naturelle.

La consultation de ses premières commandes et factures atteste des hautes compétences et connaissances d'une jeune femme de 30 ans. Au printemps 1960 arrivent les outils de travail fondamentaux : anthologies de littérature classique et contemporaine, premières œuvres complètes d'écrivains comme Miyazawa Kenji 宮 沢賢治 (1896-1933), poète et auteur de contes, des études de référence comme le Bungaku ni arawaretaru waga kokumin shisō no kenkyū 文学に現れたる我が国民 思想の研究 (Études sur la pensée du peuple japonais dans la littérature; 1917-1921) de Tsuda Sōkichi 津田左右吉 (1873-1961), un des pionniers de l'histoire culturelle du Japon. Dès lors, Isseidō effectue ses livraisons avec régularité.

L'histoire n'est pas en reste, loin s'en faut ! Madame Fujimori acquiert les grands recueils de documents tels que le Dai-Nihon komonjo 大日本古文書, le Dai-Nihon shiryō 大日本史料, ainsi que des collections d'ouvrages de haute vulgarisation, comme le Jinbutsu sōsho 人物叢書 (Collection biographique) qui démarre en 1958, année de sa prise de fonction. Ladite collection, dans un style simple, brosse le portrait de personnages liés à l'histoire du Japon, étrangers inclus. Elle porta une attention vigilante aux collections d'histoire de collectivités locales qui jouèrent un rôle prééminent dans l'histoire du Japon et incluant des recueils de documents primaires. Citons, entre autres, les volumes sur l'histoire de la ville et du département d'Ōsaka, des villes de Kamakura, Yokohama et Nara et du département de Nagasaki.

Elle n'oublia pas les outils bibliographiques de référence comme le Kokusho sōmokuroku 国書総目録 (Catalogue général des imprimés japonais).

Très rapidement, la linguistique fait une entrée en force avec des études de très haut niveau, des œuvres d'éminents linguistes tels que Kindaichi Haruhiko 金 田一春彦 (1913-2004), des titres majeurs en grammaire, lexicologie, histoire 
de la langue et études de dialectologie qui incluent le groupe des dialectes de la langue de l'archipel méridional des Ryūkyū apparentée au japonais ancien et la langue ainu, spécialité de Kindaichi Kyōsuke 金田一京助 (1882-1971), père de Haruhiko. Aujourd'hui, la Bulac, grâce à ce travail accompli, est le pôle de référence en France pour la linguistique japonaise.

Elle ne négligea pas pour autant la recherche en anthropologie. Citons les œuvres complètes des deux auteurs majeurs que sont Yanagita Kunio 柳田國 男 (1875-1962) et Origuchi Shinobu (Nobuo) 折口信夫 (1887-1953).

En outre, dans les années 1980-1990, sont publiées les rééditions en fac-similé de périodiques littéraires et artistiques du début du $\mathrm{Xx}^{\mathrm{e}}$ siècle tels que Hototogisu ホトトギス (Le coucou), revue littéraire du tournant du $\mathrm{xx}^{\mathrm{e}}$ siècle fondée par des amis du poète Masaoka Shiki 正岡子規 (1867-1902) qui publia en 1905 un des plus célèbres romans de Natsume Sōseki 夏目漱石 (1867-1916), Wagahai wa neko de aru 吾輩は猫である (Je suis un chat). Madame Fujimori s'empressa d'acquérir de tels documents, hors de prix, mais essentiels à la recherche sur l'histoire littéraire et artistique des débuts du Japon contemporain.

Elle fut par ailleurs étroitement associée à la logistique des épreuves de l'agrégation de japonais créée en 1984 à l'initiative du professeur Jean-Jacques Origas (1937-2003) en procurant les documents nécessaires aux épreuves écrites et orales.

Elle fut aussi attentive à la conservation des documents anciens qui, depuis plus d'un siècle, accumulaient de vénérables couches de poussière. Elle obtint une substantielle subvention de la Fondation de France pour équiper les manuscrits et imprimés de l'époque d'Edo et du début de l'ère Meiji d'étuis bleus sur mesure et fermés par des onglets.

Enfin et surtout, au-delà de ses compétences professionnelles hors pair, Madame Fujimori a suscité auprès de ceux qui l'ont connue admiration et respect par sa dignité, sa force de caractère, son équanimité, son élégance morale, son attention et sa disponibilité envers tous quel que soit le niveau de chacun.

Son aide précieuse et sans faille à des générations d'étudiants, de chercheurs et d'enseignants a largement contribué à la renommée des études japonaises en France. Qu'elle en soit remerciée ! 
